\title{
Diagnosis and preoperative tagging of duodenal gastrinoma by endoscopic ultrasound
}

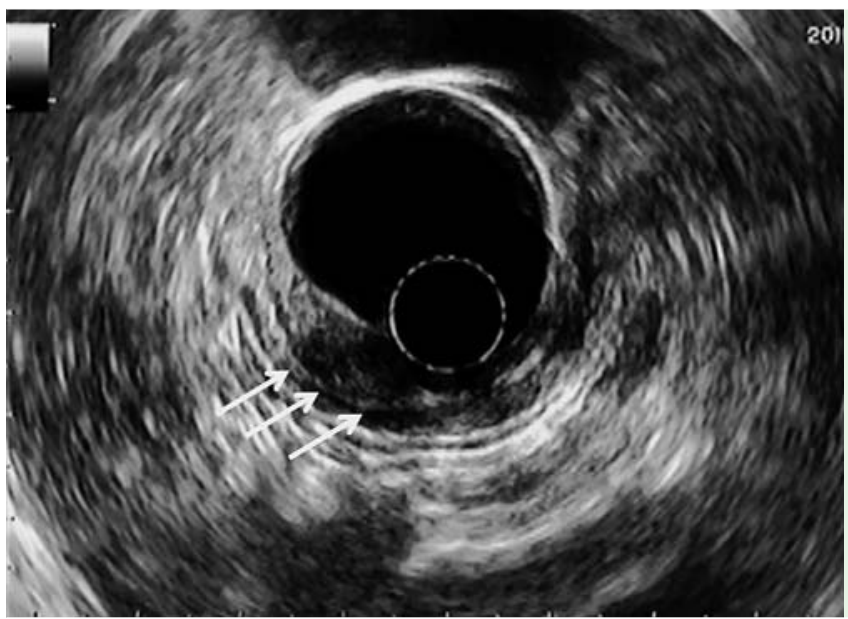

Fig. 1 Endoscopic ultrasound showing a hypoechoic, welldefined, 10-mm submucosal lesion of the duodenal bulb (arrows), without invasion of the muscularis propria, in a 57-year-old man presenting with chronic diarrhea of 6 years' duration.
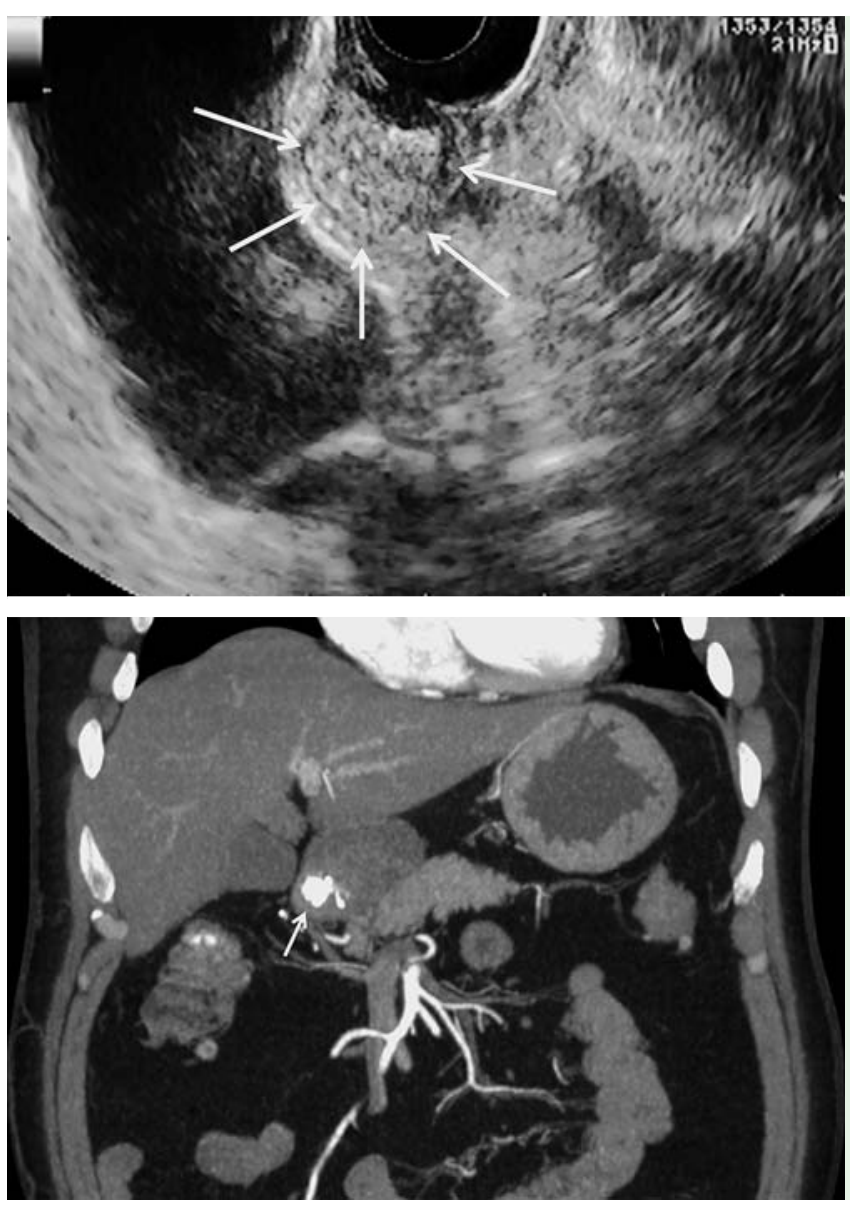

Fig. 2 Endoscopic ultrasound visualization of the duodenal gastrinoma (arrows) at the end of the tagging procedure.

Fig. 3 Computed tomography 5 hours after the procedure demonstrating a Lipiodol tag (arrow).

Almost $50 \%$ of sporadic duodenal gastrin-expressing neuroendocrine tumors (NETs), so-called gastrinomas, are associated with Zollinger-Ellison syndrome (ZES). The risk for lymph node metastasis is high $(40 \%-70 \%)$, even in tumors smaller than $10 \mathrm{~mm}$ [1]. We report the endoscopic ultrasound (EUS) diagnosis of a case of sporadic duodenal gastrinoma manifesting with ZES.

A 57-year old man presented with chronic diarrhea that had lasted for 6 years. Upper gastrointestinal endoscopy showed multiple ulcerations of the second part of the

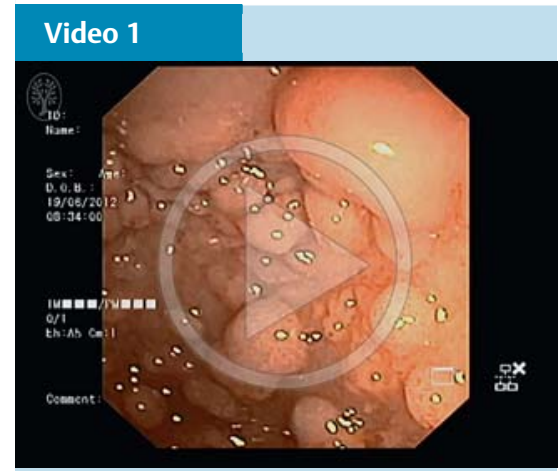

During upper gastrointestinal endoscopy with a side-viewing scope, a submucosal lesion of the bulb in an immediately post-pyloric location is observed and biopsied. The bulb exhibits a diffuse Brunner's gland hyperplasia.

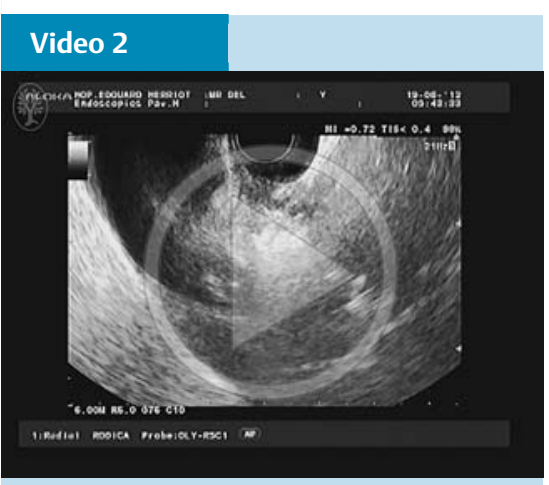

Endoscopic ultrasound-guided tagging of the tumor with $0.4 \mathrm{~mL}$ of contrast agent.

duodenum. The patient's high levels of gastrin and chromogranin A (two and four times the normal values, respectively) and proton pump inhibitor-sensitive diarrhea were suggestive of ZES.

The results of computed tomographic enterography and somatostatin receptor scintigraphy were normal. EUS showed a hypoechoic, well-defined, 10-mm submucosal lesion of the duodenal bulb ( $\bullet$ Fig. 1 ), without invasion of the muscularis propria, and two suspicious periduodenal lymph nodes. The lesion was then visualized with a side-viewing scope ( $\bullet$ Video 1 ), and biopsy confirmed a well-differentiated NET. Surgical resection after endoscopic tagging of the lesion was proposed. Because of the immediately post-pyloric location of the lesion, tagging with clips was precluded. Under EUS guidance, a curvilinear echoendoscope (GF-UCT140; 


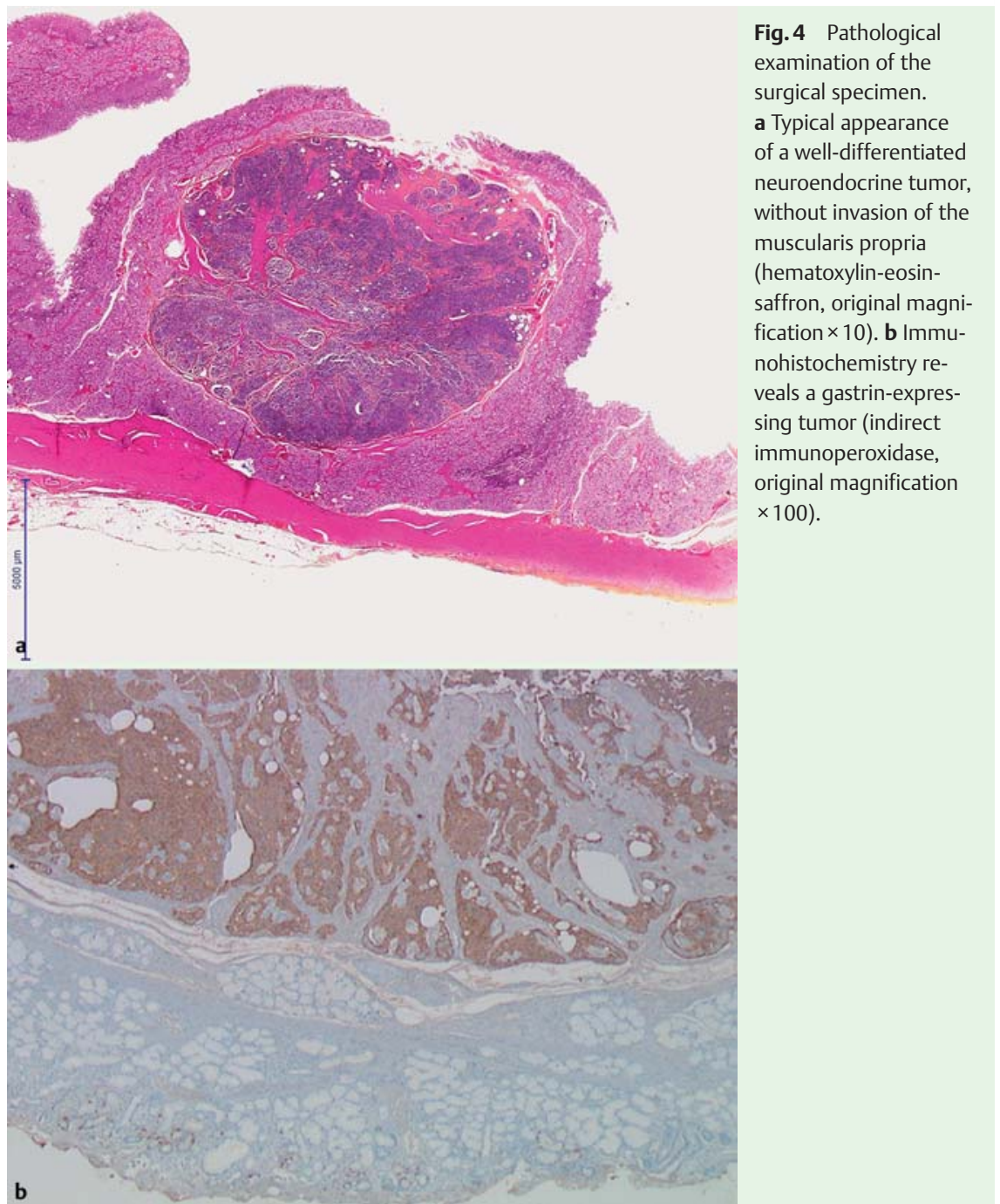

Olympus, Tokyo, Japan) and a 22-gauge needle (Wilson-Cook Medical, WinstonSalem, North Carolina, USA) ( Fig. 2 , - Video 2) were used to inject $0.4 \mathrm{~mL}$ of contrast agent (Lipiodol; Guerbet, Bloomington, Indiana, USA) into the tumor. The tag was seen at computed tomography 5 hours later ( $\bullet$ Fig. 3).

Duodenectomy with antrectomy and lymph node dissection were performed. Pathological examination confirmed a
Endoscopy_UCTN_Code_TTT_1AS_2AB

Competing interests: None

\section{Rodica Gincul' ${ }^{1}$, Vincent Lepilliez ${ }^{1}$, Thomas Walter ${ }^{1,2}$, Maud Rabeyrin ${ }^{3}$, Thierry Ponchon' ${ }^{1}$, Mustapha Adham ${ }^{4}$, Jean-Alain Chayvialle ${ }^{1,2}$}

${ }^{1}$ Department of Gastroenterology, Edouard Herriot Hospital, Hospices Civils de Lyon, Lyon, France

2 Université Claude Bernard Lyon 1, Lyon, France

${ }^{3}$ Department of Pathology, Edouard Herriot Hospital, Hospices Civils de Lyon, Lyon, France

${ }^{4}$ Department of Digestive Surgery, Edouard Herriot Hospital, Hospices Civils de Lyon, Lyon, France

\section{Reference}

1 Scherübl H, Jensen R, Cadiot $G$ et al. Neuroendocrine tumors of the small bowels are on the rise: early aspects and management. World J Gastrointest Endosc 2010; 2: 325 334

\section{Bibliography}

DoI http://dx.doi.org/

10.1055/s-0034-1393235

Endoscopy 2015; 47: E504-E505

(C) Georg Thieme Verlag KG

Stuttgart · New York

ISSN 0013-726X

\section{Corresponding author}

\section{Rodica Gincul, MD}

Gastroenterology

Edouard Herriot Hospital

5 Place d'Arsonval

69437 Lyon

Cedex 03

France

Fax: +33-472110147

rodica.gincul@chu-lyon.fr 